\title{
DO MICRO SMALL MEDIUM ENTERPRISES (MSMES) NEED MODERN MANAGEMENT ACCOUNTING TECHNIQUES? AN INDONESIAN PERSPECTIVE
}

\author{
Amanda Acintya ${ }^{{ }^{*}}$ \\ ${ }^{1}$ Department of Accounting, Faculty of Economics and Business, Universitas Gadjah Mada, \\ Yogyakarta, 55281, Indonesia
}

\section{ABSTRACT}

Introduction/Main Objectives: Management accounting practices (MAPs) have long been recognized as a subject of interest with regards to business performance, including for Micro Small Medium Enterprises (MSMEs). Despite the significant role of this sector in emerging countries, there is a dearth of research into the practical implementation of MAPs. Background Problems: The purpose of this paper is to gain a general understanding of whether modern and traditional MAPs, in the MSMEs' context, are on an equal footing in terms of usage and perceived importance. We adopt the IFAC's management accounting (MA) evolution model to structure this research. Novelty: This study contributes by tracing the adoption of MAPs as an indicator of the MSMEs' need for MA information. Within an academic and regulatory framework, this study is believed to provide an important contribution for academicians, practitioners and the government. Research Methods: We conducted an attended survey of 34 MSMEs around Yogyakarta and used the simple yet meaningful statistical technique of descriptive analytics. Finding/Results: The findings indicate that traditional MAPs (the ones in IFAC stages 1 and 2) were found to be marginally better implemented than the modern MAPs (IFAC stages 3 and 4). We compute the difference of two proxies: extent of implementation (EI) and perceived importance (PI) as an indicator of the gap in their operationalization. We found that as the IFAC stage moves along to the modern MAPs spectrum, the average difference between EI-PI also moves up accordingly. Conclusion: Hence, despite the better implementation of traditional MAPs among the MSMEs, it does not eliminate the opportunity for the increasing usage of modern MAPs in the future.

\section{ARTICLE INFO}

Article history:

Received 3 January 2020

Received in revised form

20 February 2020

Accepted 23 February

2020

Keywords:

management accounting practices, MSMEs, management accounting evolution, Indonesian MSMEs, management accounting techniques

JEL Code:

A1, A2, M41

\footnotetext{
* Corresponding Author at Department of Accounting, Faculty of Economics and Business, Universitas Gadjah Mada, Jalan Socio Humaniora No. 1, Yogyakarta 55182, Indonesia.

E-mail address: amandaacintya@ugm.ac.id
} 


\section{INTRODUCTION}

In the end of $19^{\text {th }}$ century, the academic world recognized a significant gap between theoretical and practical knowledge in the context of management accounting (MA). Although efforts to shape accounting practices around mathematical techniques were notable, these techniques were unsuccessful at being adopted by businesses, even well established firms, let alone by Micro Small Medium Enterprises (MSMEs). Hence, there are prevalent pressures for an in-depth understanding of management accounting practices (MAPs) (Ittner \& Larcker, 2002).

MSMEs are known for their adaptability and agility, enabling them to survive significant business uncertainties, as well as being able to survive during a recession (Mitchell and Reid, 2000). Nevertheless, survival is a growing concern as the majority of business owners are perceived to "have little or no conception of workings” (Kirby and King, 1997). Past literature has documented the idea that MSMEs poor performance was a result of their failure to accurately implement MAPs (Hopper et al., 1999; Nandan, 2010; Lucas et al., 2013).

The research into the practicality of MAPs, in the context of MSMEs, brings about the opportunity for empirical research that is important for two reasons. First, MSMEs contribute to the majority of developing economies, such as those found in ASEAN countries. For instance, MSMEs in Indonesia, Thailand and Malaysia constitute up to $98 \%$ of the total number of businesses (Tambunan, 2008). As a result, understanding the type and extent of MAPs implementation in this pivotal sector provides insights into which MAPs are beneficial and help them to survive and prevail.

Secondly, despite the economic and social importance of SMEs, there is a lack of research studying the provision of management accounting information and the use of management accounting techniques by SMEs (Nandan, 2010). The dearth of research is caused by the growing number of large enterprises that symbolize a prosperous and sophisticated business environment (Kaplan, 1990). Such a notion unavoidably skews the focus of empirical research toward the big companies that are commonly found in developed countries (Hyvonen, 2005; AbdelKader \& Luther, 2008; Angelakis et al., 2010).

Hyvonnen (2005), Abdel-Kader \& Luther (2008), Angelakis et al. (2010) and Armitage, Webb and Glynn (2015) investigated the extent of MAPs implementation in their respective countries, namely Finland, the UK, Greece, Australia and Canada. Whilst the results were non-conclusive, a pattern did arise. In general, traditional MA techniques were found to be implemented marginally better than the more sophisticated techniques, except for Greek companies. The study by Angelakis et al. (2010) indicated that some modern MA techniques were implemented very well by the big companies in Greece.

Overall, the research investigating MAPs in SMEs is considered to be lacking and fragmented, leaving an empty void for further studies to examine (Ahmad, 2017), for two reasons. First, previous studies have mostly been conducted in developed economies, while only a few were undertaken in an emerging country like Indonesia. Second, this study provides empirical evidence on the usage, the extent of implementation and the perceived importance of MAPs in the context of MSMEs. In this respect, we believe this study provides an important contribution for academicians, practitioners and regulatory bodies to understand the SMEs attitude towards traditional and modern MAPs. Built upon MA evolution theories, this study displays a narrative that explains the develop- 
ments in MAPs' implementation that marks the point at which MSMEs became key players within the wider economy. Last, we provide a theoretical framework for MA than can be adapted for any context.

In this paper, there are two questions we try to answer:

1. Are traditional and modern MAPs equally implemented by MSMEs?

2. Do MSMEs perceive modern MAPs as important?

The remainder of this paper is structured as follows. In the next section, we present the theoretical framework of the IFAC MA model. Next, we provide the methodological approach followed by analysis of the results and discussions. The final section presents conclusions and implications for future research.

\section{THEORETICAL BACKGROUND}

\section{The Landscape of Indonesian MSMEs}

In the past decade researchers have made an increased effort to investigate MSMEs, due their dominant role. Globally, MSMEs represent 99\% of the business players. Similarly, Indonesia is characterized with grassroots MSMEs that make up $99.95 \%$ of the total number of enterprises. There are 41 million micro and small business units which account for over $40 \%$ of Indonesia's GDP. As for medium enterprises, there are 60,000 units that contribute $16 \%$ of the national economy. Accordingly, MSMEs are commonly agreed to be critical to the long-term growth of a nation.

The Government of Indonesia (GoI) is cognizant of the MSMEs' key role in economic growth and mobility. The MSME sector is also featured in the Indonesian Medium-Term
Development Plan 2015-2019, making MSMEs part of the nation's top priority. Nevertheless, the sector is similar to larger organizations, with respect to its business threats. Factors like technology development, capital constraints, globalization, and market competition are challenges any business needs to manage. For a business to be sustainable and compete, Senftlechner and Hiebl (2015) highlighted the equal importance of financial and non-financial information. For this reason, MA is regarded as pivotal for strengthening managerial functions.

\section{IFAC Management Accounting Model}

In an effort to translate the result into a more meaningful and coherent finding, we believe there is a need to adopt a structured and logical framework. With that regard, we adopt IFAC's holistic approach and use the management accounting model. IFAC provides a conceptual framework presenting the development of MA within four stages of the "evolution" model (Figure 1). In 1998, IFAC produced "Management Accounting Practice Statement Number 1." This statement contains a general conception of management accounting, for instance, the scope, purposes and the underpinning principles. Using this framework, scholars developed an evolution model of management accounting to map out the different maturity stages of MAPs (Abdel-Kader \& Luther, 2006). These stages are not mutually exclusive as each stage incorporates the concepts from the previous stage and the ones arising in that stage. For example, Stage 2 includes all MAPs that are included in Stage 1 as well as those arising at Stage 2. Given the evolutionary nature of the MAPs, there was some criticism that the boundaries of these four stages were not very vivid (Waweru, 2010). 


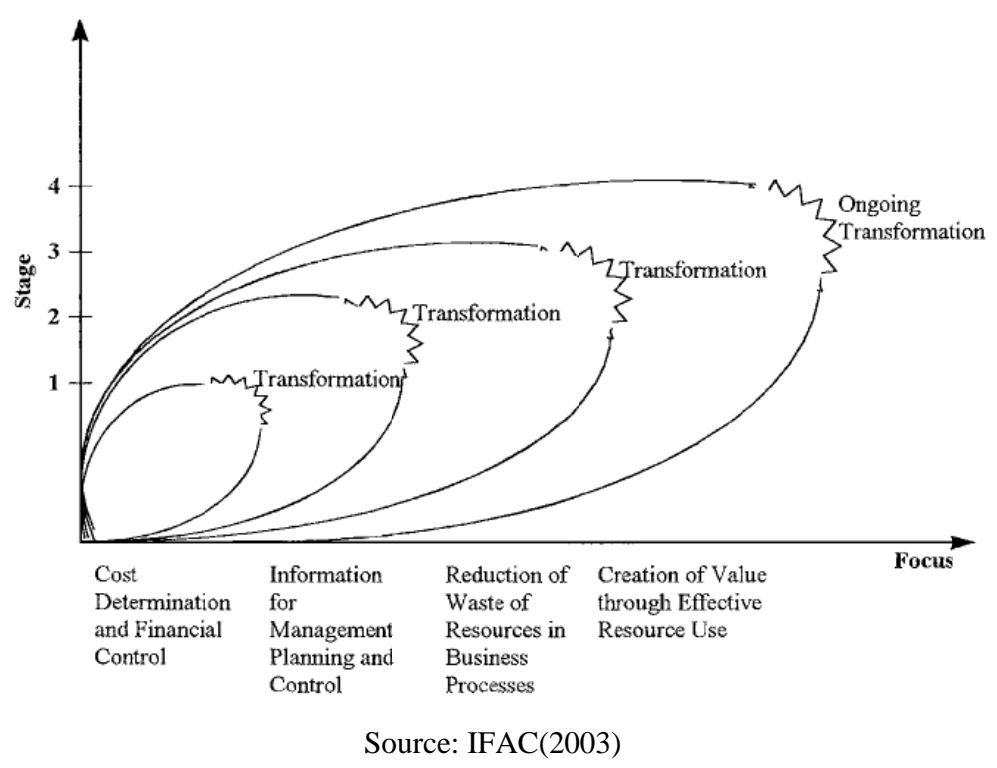

Figure 1. IFAC’s Management Accounting Evolution Model

The IFAC's first stage is called "Cost Determination and Financial Control” with the main focus on product costing. This stage was characterized by its technical activities and homogenous production process so that direct costs were traceable and overhead costs were assigned using a single driver, such as direct labor hours. Budgeting and other cost accounting techniques were tools commonly used by management to control the production costs and processes. However, the output of these techniques was poorly utilized in managerial decision making.

The IFAC's second stage "Information for Management Planning and Control" is defined as "a management activity, yet in a staff role" (Abdel-Kader, 2006). The role of MA shifted to provide information for management's planning and controlling functions. Despite the changing role, MA-supported decisions still tended to be reactive, and action plans were formulated for any planning deviations. Technology's usage was still at its infancy, and most of the significant internal administration was still done manually.
The third stage spans from 1965 to 1984 and is called "Reduction of Waste," when the rapid development and usage of technology became prevalent. Compared to the second stage, information became more valuable and deemed to be an organizational resource in this later stage. The use of computers allowed managers to access real-time data easily and respond to increasing competition. Firms were not only focusing on the reduction of costs, but also waste. Management accounting was even more pivotal to ensure information was available for employees at all levels.

The IFAC's last stage, the "Value Creation" phase, began in 1995 when management accountants played a major role to create value through the effective use of resources. IFAC defined this stage as "the use of technologies which examine the drivers of customer value, shareholder value and organizational innovation."

To systematically classify MAPs into their traditional and modern nature, this research needs to operationalize the IFAC's MA evolution model. Considering the IFAC's stages evolved 
through time, researchers differentiate the MAPs into traditional (stages 1 and 2) and modern (stages 3 and 4). To assign MAPs to each respective IFAC stage, we adopted 29 MAPs from Nishimura (2005), Abdel-Kader and Luther (2006); Angelakis, Theriou and Floropoulos
(2010); Cuzdriorean (2017) as follows Table 1.

\section{METHOD, DATA, AND ANALYSIS}

We used a survey to address these research objectives: (1) understanding whether MSMEs in Indonesia implement traditional and modern

Table 1. The Operationalization of MAPs to IFAC's Conception Model

\begin{tabular}{|c|c|c|c|}
\hline MAP Maturity & IFAC Stage & & Type of MAP \\
\hline \multirow{7}{*}{ Traditional } & \multirow{7}{*}{$\begin{array}{c}\text { Stage } 1 \\
\text { Cost Determination and } \\
\text { Financial Control } \\
\text { (CDFC) }\end{array}$} & CDFC 1 & Standard costing \\
\hline & & CDFC 2 & Budgeting for controlling costs \\
\hline & & CDFC 3 & Budget for daily operations \\
\hline & & CDFC 4 & Flexible budgeting \\
\hline & & CDFC 5 & Break-even point analysis \\
\hline & & CDFC 6 & Performance evaluation based on financial measures \\
\hline & & CDFC 7 & $\begin{array}{l}\text { Payback period and/or accounting rate of return for } \\
\text { capital investment evaluation }\end{array}$ \\
\hline \multirow{9}{*}{ Traditional } & \multirow{9}{*}{$\begin{array}{c}\text { Stage } 2 \\
\text { Information for } \\
\text { Management Planning } \\
\text { and Control (IPC) }\end{array}$} & IPC 1 & Absorption and variable costing \\
\hline & & IPC 2 & Budgeting for planning \\
\hline & & IPC 3 & Cost volume profit analysis \\
\hline & & IPC 4 & Product profitability analysis \\
\hline & & IPC 5 & Variance analysis \\
\hline & & IPC 6 & Performance evaluation based on operational measures \\
\hline & & IPC 7 & Formal strategic planning \\
\hline & & IPC 8 & Long-range forecasting \\
\hline & & IPC 9 & $\begin{array}{l}\text { Investment evaluation using discounted cashflow } \\
\text { (NPV, IRR) }\end{array}$ \\
\hline \multirow{7}{*}{ Modern } & \multirow{7}{*}{$\begin{array}{c}\text { Stage } 3 \\
\text { Reduction of Waste of } \\
\text { Resources in Business } \\
\text { Process (RWR) }\end{array}$} & RWR 1 & Activity-based costing \\
\hline & & RWR 2 & Quality costing \\
\hline & & RWR 3 & Zero-based budgeting \\
\hline & & RWR 4 & Activity-based management \\
\hline & & RWR 5 & Balanced scorecard \\
\hline & & RWR 6 & $\begin{array}{l}\text { Performance evaluation based on employee-related } \\
\text { measures }\end{array}$ \\
\hline & & RWR 7 & $\begin{array}{l}\text { Sensitivity "what if” analysis for capital investment } \\
\text { evaluation }\end{array}$ \\
\hline \multirow{6}{*}{ Modern } & \multirow{6}{*}{$\begin{array}{c}\text { Stage } 4 \\
\text { Creation of Value } \\
\text { through Effective } \\
\text { Resource Use (VC) }\end{array}$} & VC 1 & Target costing \\
\hline & & VC 2 & Benchmarking \\
\hline & & VC 3 & Customer profitability analysis \\
\hline & & VC 4 & Residual Income and EVA \\
\hline & & VC 5 & Customer satisfaction survey \\
\hline & & VC 6 & Hurdle rate for capital investment evaluation \\
\hline
\end{tabular}


MAPs equally; (2) exploring if MSMEs perceive modern MAPs to be as important as the traditional MAPs. After that, we measured the extent of the MAPs' implementation and their perceived importance to the respondents, using each of the 29 MAPs (as seen in Table 1) that we identified through the past literature. The usage of a MAP is measured through a simple "Yes/No" statement while the extent of its implementation and perceived importance is measured with a five point Likert scale.

A total of 34 responses were collected through an attended survey undertaken over two months at MSMEs in Yogyakarta region, in Indonesia. Given the potential issue with financial terminology and literacy, we used an attended survey to ensure each question was fully understood. This process is vital due to the complexities in each MAP, and relying on only a survey might lead to potential personal bias and judgment errors (Cuzdriorean, 2017). In an attempt to get consistent responses to the questionnaire, each MAP was discussed to establish standardized language and to reach a common understanding among the surveyors.

\section{RESULT AND DISCUSSION}

\section{Structure and Profile of Indonesian MSMEs}

Table 2 summarizes the profile of our 34 respondents, i.e. the type of industry, number of employees and annual revenues. Despite the limited number of respondents, we were satisfied that our sample had a wide variety of industries and sizes to anticipate the possible differences in the usage of MAPs due to differing company characteristics. Furthermore, our respondents were limited to business owners and operations managers who had the expertise to provide sound responses.
To classify the SMEs' sector, we adopted the MSME classification based on the government's Indonesia Constitution no. 20 the year 2008 using the number of employees and annual sales revenue. Based on annual sales classification, $53 \%$ of our respondents were small companies, $44 \%$ were micro, and only 3\% were considered as medium enterprises. With regards to the number of employees, the majority of our respondents ( $\sim 88 \%$ ) were small enterprises, with the number of employees ranging from 5 to 20 while the remaining ones were in the mediumsized sector.

Table 2. MSME's Profiles and Descriptive Statistics

\begin{tabular}{lcc}
\hline By sales turnover & No & $\%$ \\
<Rp 300 Million & 15 & $44 \%$ \\
Rp 300 Million - Rp 2,5 Billion & 18 & $53 \%$ \\
Rp 2,5 Billion - Rp 50 Billion & 1 & $3 \%$ \\
By number of employees & & \\
1-10 & 25 & $73 \%$ \\
$10-20$ & 5 & $15 \%$ \\
$20-40$ & 3 & $9 \%$ \\
$>40$ & 1 & $3 \%$ \\
By industry & & \\
$\quad$ Manufacturing & 10 & $29 \%$ \\
Service & 8 & $24 \%$ \\
Food Industry & 13 & $38 \%$ \\
Merchandising & 3 & $9 \%$ \\
\hline
\end{tabular}

\section{Usage of MAPs}

To answer the first research question, we identified the practical usage of each IFAC stage and each MAP. First, we discussed the average (mean) MAPs usage for each IFAC stage, to set the background and gain an understanding of the popularity of traditional vs. modern MAPs, in the context of the MSMEs. As depicted in Table 3 , the mean usage of MAPs decreases as the IFAC maturity stage goes up, except for Stage 3. Among our respondents, $78 \%$ claimed to have been using MAPs in Stage 1 and 75\% in Stage 2. 
However, a steep decrease is notable in the transition from the two traditional stages to the modern stages. We found that the mean usage of Stage 3 MAPs was $47 \%$. Interestingly, the usage bounced back to $61 \%$ for the most modern MAPs in IFAC Stage 4. As the mean usage of modern MAPs in stages 3 and 4 is significantly lower than the ones in stages 1 and 2, this research finding indicates that our respondents are more inclined to use traditional MAPs than modern MAPs.

Table 3. Mean Value of MAP Usage Rate (per Practice and per Stage)

\begin{tabular}{|c|c|c|c|}
\hline $\begin{array}{l}\text { IFAC } \\
\text { Stage } \\
\end{array}$ & MAP & $\begin{array}{l}\text { Mean } \\
\text { Usage }\end{array}$ & Usage \\
\hline \multirow{7}{*}{$\begin{array}{l}\text { Stage 1- } \\
\text { CDFC }\end{array}$} & CDFC 1 & \multirow{7}{*}{$78 \%$} & $94 \%$ \\
\hline & CDFC 2 & & $79 \%$ \\
\hline & CDFC 3 & & $74 \%$ \\
\hline & CDFC 4 & & $71 \%$ \\
\hline & CDFC 5 & & $85 \%$ \\
\hline & CDFC 6 & & $91 \%$ \\
\hline & CDFC 7 & & $50 \%$ \\
\hline \multirow{9}{*}{$\begin{array}{c}\text { Stage } 2- \\
\text { IPC }\end{array}$} & IPC 1 & \multirow{9}{*}{$75 \%$} & $88 \%$ \\
\hline & IPC 2 & & $71 \%$ \\
\hline & IPC 3 & & $65 \%$ \\
\hline & IPC 4 & & $94 \%$ \\
\hline & IPC 5 & & $74 \%$ \\
\hline & IPC 6 & & $94 \%$ \\
\hline & IPC 7 & & $74 \%$ \\
\hline & IPC 8 & & $85 \%$ \\
\hline & IPC 9 & & $29 \%$ \\
\hline \multirow{7}{*}{$\begin{array}{c}\text { Stage } 3 \text { - } \\
\text { RWR }\end{array}$} & RWR 1 & \multirow{7}{*}{$47 \%$} & $32 \%$ \\
\hline & RWR 2 & & $74 \%$ \\
\hline & RWR 3 & & $29 \%$ \\
\hline & RWR 4 & & $26 \%$ \\
\hline & RWR 5 & & $18 \%$ \\
\hline & RWR 6 & & $91 \%$ \\
\hline & RWR 7 & & $59 \%$ \\
\hline \multirow{6}{*}{$\begin{array}{c}\text { Stage } 4- \\
\text { VC }\end{array}$} & VC 1 & \multirow{6}{*}{$61 \%$} & $85 \%$ \\
\hline & VC 2 & & $88 \%$ \\
\hline & VC 3 & & $79 \%$ \\
\hline & VC 4 & & $15 \%$ \\
\hline & VC 5 & & $88 \%$ \\
\hline & VC 6 & & $12 \%$ \\
\hline
\end{tabular}

While the usage rate for modern MAPs in IFAC Stage 3 and Stage 4 are lower and more widely dispersed, our respondents assert they have been using traditional MAPs the majority of the time. It is worth noticing that most MAPs in Stage 1 and Stage 2 have a moderate to high usage rate, except for investment evaluation using a discounted method like Net Present Value (NPV) and Internal Rate Return (IRR) with usage rate of $29 \%$. This finding is consistent if we look further down the table. It can be inferred that the least adopted MAPs were the techniques related to capital investment evaluation, i.e. residual income/Economic Value Added (EVA) and the hurdle rate with respective usage of $15 \%$ and $12 \%$. Both MAPs are modern MAPs that belong to IFAC Stage 4.

Secondly, our research enables us to look closely at the usage of an individual MAP. As displayed in the table, some of the most commonly used MAPs are standard costing, product profitability analysis and the use of operation-related measures. Each of these MAPs has a usage rate of $94 \%$. Our results reassert the past findings that accounting techniques related to cost and management controls were essential and tend to be used frequently (Hyvonen, 2005). In parallel, 91\% of our respondents claimed they have been using financial and employee-related performance indicators. Those five most used MAPs, as mentioned above, are labeled as traditional MAPs, except for employee indicators. In general, this finding confirms the notion from past literature that traditional MAPs are more commonly preferred than modern MAPs (Chenhall and Smith, 1998; Laureano, Machado, and Laureano, 2016; Cuzdriorean, 2017) mainly for the purpose of control (Ahmad, 2017). 


\section{Implementation and Perceived Importance of MAPs}

To have a deeper understanding of the practicality of a MAP, we calculate the mean score of the extent of implementation and perceived importance for each IFAC stage (Table 4) and MAP (Table 5). We believe these two indicators are important since MSMEs might give a high score to importance, but it is not a particularly meaningful indicator without a high degree of implementation, and vice versa. As both indicators provide complementary information, we aim to answer these questions: Whether the low adoption of certain MAPs is because MSMEs don't see them as important, or whether MSMEs are infrequent adopters despite their claim to have implemented MAPs?

Along with the previous section, our analysis is done on two levels: per IFAC Stage and per individual MAP. First, as seen in Table 4, the MSMEs mostly claimed to have implemented MAPs from all the IFAC stages, although to a rather moderate extent of implementation (EI). Out of the five Likert scales, the average implementation decreases incrementally from 3.37 for Stage 1 to 2.79 for Stage 4. With regards to perceived importance (PI), we found a similar pattern in which the importance score declines from the traditional stages to the mature stages (4.15 in Stage 1 to 3.80 in Stage 4). The highest implementation and perceived importance scores are for the MAPs in Stage 1; this confirms the notion that traditional MAPs bring more benefits than the newer ones do (Chenhall and Smith, 1998; Ahmad, 2017).
Focusing on the descending trend of EI, our findings are in alignment with the postulate of the IFAC model. Here, we found that the extent of MAPs' implementation is highest at the lowest stage. Theoretically, the implementation in Stage 1 should be highest, as it is a foundation and it is followed by a lesser extent of implementation in the later stages. It is interesting however, that the score for both the implementation and importance of Stage 3 is lower than Stage 4. Looking further at the individual MAPs in Table 3, this low score is contributed by balanced scorecard and discounted capital investment evaluation (NPV, IRR). Our finding is contrary to the research in developed countries that documented a high usage of capital budgeting i.e. 88\% in Finnish firms (Hyvonen, 2005) and 92\% (Chenhall and Langfield-Smith, 1998) in Australian firms. In these countries, capital budgeting measures ranked number three and two respectively.

In addition, we compute the difference between EI and PI and the number is a simple indicator for the gap in operationalization. We found that as the IFAC stages move closer to the modern MAPs' spectrum, the average gap between implementation-importance also moves up accordingly. The widely-held argument that SMEs do not need modern MAPs is likely flawed because our finding indicates that despite the low adoption/implementation by SMEs, business owners regard modern MAPs as important.

Table 4. Mean Values of Implementation and Perceived Importance of MAPs (per stage)

\begin{tabular}{lccc}
\hline \multicolumn{1}{c}{ IFAC Stage } & $\begin{array}{c}\text { Extent of } \\
\text { Implementation (EI) }\end{array}$ & $\begin{array}{c}\text { Perceived } \\
\text { Importance (PI) }\end{array}$ & $\begin{array}{c}\text { Gap } \\
\text { (EI - PI) }\end{array}$ \\
\hline Stage 1- CDFC & 3.37 & 4.15 & -0.78 \\
Stage 2 - IPC & 3.14 & 4.11 & -0.97 \\
Stage 3 - RWR & 2.40 & 3.68 & -1.28 \\
Stage 4 - VC & 2.79 & 3.80 & -1.01 \\
\hline
\end{tabular}


Secondly, at the individual MAP's level (Table 5), we found that the highest extent of MAP implementation correlates with our previous finding on the usage of MAPs. MAPs with the most usage i.e. standard costing, product profitability analysis, and financial and operation measurements are also among the
MAPs with the highest extent of implementation. Also, break-even point is considered to be implemented extensively. Again, all these five highly implemented MAPs are categorized as traditional techniques and belong to either IFAC Stage 1 or 2 .

Table 5. Mean Values of Implementation and Perceived Importance of MAPs (per Practice)

\begin{tabular}{|c|c|c|c|c|c|c|c|}
\hline \multirow[t]{2}{*}{ IFAC Stage } & \multirow[t]{2}{*}{ MAP } & \multicolumn{2}{|c|}{$\begin{array}{c}\text { Extent of } \\
\text { Implementation } \\
\text { (EI) } \\
\end{array}$} & \multicolumn{2}{|c|}{$\begin{array}{c}\text { Perceived } \\
\text { Importance } \\
\text { (PI) } \\
\end{array}$} & \multicolumn{2}{|c|}{$\begin{array}{c}\text { Gap } \\
\text { (EI - PI) }\end{array}$} \\
\hline & & Mean & SD & Mean & SD & Mean & SD \\
\hline \multirow{7}{*}{$\begin{array}{l}\text { Stage 1- } \\
\text { CDFC }\end{array}$} & CDFC 1 & 3.74 & 1.14 & 4.21 & 0.88 & -0.47 & 6.79 \\
\hline & CDFC 2 & 3.32 & 1.43 & 4.21 & 0.73 & -0.88 & 7.52 \\
\hline & CDFC 3 & 3.35 & 1.55 & 4.12 & 0.81 & -0.76 & 8.14 \\
\hline & CDFC 4 & 3.09 & 1.44 & 3.74 & 0.96 & -0.65 & 7.33 \\
\hline & CDFC 5 & 3.74 & 1.40 & 4.44 & 0.66 & -0.71 & 7.83 \\
\hline & CDFC 6 & 3.74 & 1.26 & 4.35 & 0.85 & -0.62 & 7.18 \\
\hline & CDFC 7 & 2.62 & 1.81 & 4.00 & 1.13 & -1.38 & 9.75 \\
\hline \multirow{9}{*}{ Stage 2 - IPC } & IPC 1 & 3.56 & 1.33 & 4.41 & 0.70 & -0.85 & 7.33 \\
\hline & IPC 2 & 3.12 & 1.57 & 4.18 & 0.72 & -1.06 & 7.94 \\
\hline & IPC 3 & 2.82 & 1.59 & 4.12 & 0.81 & -1.29 & 8.43 \\
\hline & IPC 4 & 3.74 & 1.26 & 4.41 & 0.70 & -0.68 & 7.32 \\
\hline & IPC 5 & 3.09 & 1.52 & 4.09 & 1.06 & -1.00 & 8.47 \\
\hline & IPC 6 & 3.85 & 1.10 & 4.35 & 0.73 & -0.50 & 6.62 \\
\hline & IPC 7 & 3.06 & 1.54 & 4.21 & 0.73 & -1.15 & 8.02 \\
\hline & IPC 8 & 3.32 & 1.34 & 4.32 & 0.73 & -1.00 & 7.26 \\
\hline & IPC 9 & 1.68 & 1.30 & 2.91 & 1.24 & -1.24 & 7.08 \\
\hline \multirow{7}{*}{$\begin{array}{c}\text { Stage } 3 \text { - } \\
\text { RWR }\end{array}$} & RWR 1 & 1.97 & 1.47 & 3.41 & 1.26 & -1.44 & 7.79 \\
\hline & RWR 2 & 3.26 & 1.56 & 4.09 & 0.93 & -0.82 & 8.38 \\
\hline & RWR 3 & 1.88 & 1.45 & 3.24 & 1.10 & -1.35 & 7.68 \\
\hline & RWR 4 & 1.79 & 1.30 & 3.38 & 1.16 & -1.59 & 6.69 \\
\hline & RWR 5 & 1.59 & 1.23 & 3.50 & 1.16 & -1.91 & 6.58 \\
\hline & RWR 6 & 3.65 & 1.23 & 4.32 & 0.81 & -0.68 & 7.20 \\
\hline & RWR 7 & 2.68 & 1.63 & 3.82 & 0.90 & -1.15 & 8.52 \\
\hline \multirow{6}{*}{ Stage 4 - VC } & VC 1 & 3.74 & 1.29 & 4.29 & 0.80 & -0.56 & 7.23 \\
\hline & VC 2 & 3.74 & 1.24 & 4.44 & 0.70 & -0.71 & 6.94 \\
\hline & VC 3 & 3.03 & 1.31 & 4.15 & 0.74 & -1.12 & 6.92 \\
\hline & VC 4 & 1.41 & 1.10 & 2.68 & 1.30 & -1.26 & 6.18 \\
\hline & VC 5 & 3.50 & 1.29 & 4.50 & 0.66 & -1.00 & 6.90 \\
\hline & VC 6 & 1.35 & 0.98 & 2.76 & 1.26 & -1.41 & 5.52 \\
\hline
\end{tabular}


Regarding the MAPs perceived importance; we found the MAPs with the highest scores can be classified into two areas: capital investment evaluation and cost controlling. The former area covers investment profitability measures like residual income and EVA while the latter area also covers profitability but with a smaller scope, which is product profitability. Within this controlling function, MSMEs also highly regard activity based management as a valuable technique (score 4.44) despite its low extent of implementation (score 1.79). Except for the product profitability, these MAPs are considered to be modern.

Looking at Table 5 above, all the MAPs have a higher score for perceived importance than for actual implementation (thus the gap is all negative). By identifying MAPs with significantly higher scores for perceived importance than for the extent of implementation, these MAPs are expected to increase their frequency of adoption (Abdel-Kader, 2006). From this finding, it is inferred that MSMEs are aware of the importance and potential benefits from applying MA techniques, but they are not properly implemented as yet. Some possible reasons are a lack of knowledge, high implementation costs, they are time-consuming and a lack of training (Cuzdriorean, 2017).

\section{Post-hoc Test}

We conducted a paired-sample t-test to identify whether or not a significant difference existed between each IFAC stage's data, as seen in Table 5 above. The details of the calculation are presented in Appendix 1. We found there was a significant difference between the stages, except for Stage 2 and Stage 3, both for the extent of implementation and perceived importance variables. This finding was anticipated because the shift from traditional to modern MAPs happens between these two stages; thus, the boundaries were permeable.

\section{CONCLUSION AND SUGGESTION}

This research aims to understand the MAPs that are most often used by MSMEs; a group that is underrepresented in today's research and academic literature. While it is impossible to draw general conclusions about the adoption of traditional and modern MAPs across geographical locations, business sizes and industry types, the result of our study is instructive.

First, we found that the most adopted MAPs are traditional techniques focusing on costing systems, product profitability analysis and nonfinancial performance measurements. This finding advocates the past literature on the inclination of MSMEs to adopt the prevailing techniques (IFAC stages 1 and 2) despite the popular claim that modern MAPs (IFAC stages 3 and 4) have more benefits for companies (AbdelKader \& Luther 2006)

Next, we mapped out each MAP into its extent of implementation and perceived importance. The result indicates that regardless of the MSMEs' moderate extent of adoption we documented their interest in adopting modern MAPs more extensively in the future.

We recognize our study was undertaken in the specific context of Yogyakarta, Indonesia, and therefore, it is important to acknowledge that certain characteristics might impact the adoption of MAPs. However, some related studies of Indonesian MSMEs are helpful to contextualize this study. First, Indonesian MSMEs are characterized as having limited skills, experience, resources, and financial support (Fatimah et al., 2013). Secondly, a study by Roostika (2019) of Yogyakarta's MSMEs showed the sector's great flexibility and adaptability for learning, so that it can stay competitive.

Future research that unveils the reasoning for the MSMEs adoption of MAPs and how MAPs would contribute to the firms' performance is of 
the utmost importance for a complete understanding of the practicality of MAPs in the context of the MSMEs.

\section{Acknowledgement (if any)}

The author would like to thank Annisa Hayatun Nazmi Burhan (Universitas Gadjah Mada) and Dinda Rosiana Hadi (Universitas Gadjah Mada) for their generous support and thoughtprovoking inputs.

\section{REFERENCES}

Abdel-Kader, M., \& Luther, R. (2006). IFAC's conception of the evolution of management accounting: A research note. Advances in management accounting, 15, 229-247, available in DOI:10.1016/S14747871(06)15010-8.

Ahmad, K. (2017). The implementation of management accounting practices and its relationship with performance in small and medium enterprises. International Review of Management and Marketing, 7(1), 342-353.

Angelakis, G., Theriou, N., \& Floropoulos, I. (2010). Adoption and benefits of management accounting practices: Evidence from Greece and Finland. Advances in accounting, 26(1), 87-96, available in DOI:10.1016/j.adiac.2010.02.003.

Armitage, H. M., Webb, A., \& Glynn, J. (2016). The use of management accounting techniques by small and medium-sized enterprises: a field study of Canadian and Australian practice. Accounting Perspectives, 15(1), 31-69, available in DOI:10.1111/1911-3838.12089.

Chenhall, R. H., \& Langfield-Smith, K. (1998). Adoption and benefits of management accounting practices: an Australian study. Management accounting research, 9(1), 119 , available in

DOI:10.1006/mare.1997.0060.

Cuzdriorean, D. D. (2017). The use of management accounting practices by Romanian small and medium-sized enterprises: A field study. Journal of Accounting and Management Information Systems, 16(2), 291-312, available in DOI:10.24818/jamis.2017.02004.

Da Silva Laureano, R. M., Cardoso Vieira Machado, M. J., \& da Silva Laureano, L. M. (2016). Maturity in management accounting: Exploratory study in Portuguese SME. Society and Economy in Central and Eastern Europe, 38(2), 139-156, available in DOI:10.1556/204.2016.38.1.

Fatimah, Y. A., Biswas, W., Mazhar, I., \& Islam, M. N. (2013). Sustainable manufacturing for Indonesian small-and medium-sized enterprises (SMEs): the case of remanufactured alternators. Journal of Remanufacturing, 3(1), 6, available in DOI 10.1186/2210-4690-3-6.

Hopper, T., Koga, T., \& Goto, J. (1999). Cost accounting in small and medium sized Japanese companies: an exploratory study. Accounting and Business Research, 30(1), 73-86, available in DOI:10.1080/00014788.1999.9728925.

Hyvönen, J. (2005). Adoption and benefits of management accounting systems: evidence from Finland and Australia. Advances in International Accounting, 18, 97-120, available in DOI:10.1016/s08973660(05)18005-2

Ittner, C., \& Larcker, D. (2002). Empirical managerial accounting research: are we just describing management consulting practice? European Accounting Review, 11(4), 787794, available in DOI:10.1080/0963818022000047082.

Kaplan, R. S. (1990). The four-stage model of cost systems design. Strategic Finance, 71(8), 22.

Kirby, D. A., \& King, S. H. (1997). Accountants and small firm development: Filling the expectation gap. Service Industries Journal, 17(2), 294-304, available in DOI:10.1080/02642069700000017.

Lucas, M., Prowle, M., \& Lowth, G. (2013). Management Accounting Practices of (UK) 
Small-Medium-Sized Enterprises (SMEs). Improving SME performance through management accounting education, Chartered Institute of Management Accountants, 9 (4), 1-13.

Nandan, R. (2010). Management accounting needs of SMEs and the role of professional accountants: A renewed research agenda. Journal of applied management accounting research, 8(1), 65-78.

Nishimura, A. (2005), The Development of Management Accounting and the Asian Position.

Roostika, R. (2019). SMEs craft industry application of resource based view: capabilities role of SMEs performance. Review of Integrative Business and Economics Research, 8, 423-440.
Senftlechner, D., \& Hiebl, M. R. (2015). Management accounting and management control in family businesses: past accomplishments and future opportunities. Journal of Accounting \& Organizational Change, 11, 573-606, available in DOI: 10.1108/JAOC-08-2013-0068.

Tambunan, T. (2008). SME development, economic growth, and government intervention in a developing country: The Indonesian story. Journal of international entrepreneurship, 6(4), 147-167, available in DOI 10.1007/s10843-008-0025-7.

Waweru, N. M. (2010). The origin and evolution of management accounting: a review of the theoretical framework. Problems and Perspectives in Management, 8 (3), 165 182 


\section{Appendix 1 Paired t-test*}

\begin{tabular}{|c|c|c|c|c|}
\hline Variable & & & t-statistic (df) & t-table \\
\hline \multirow{6}{*}{$\begin{array}{l}\text { Extent of } \\
\text { Implementation }\end{array}$} & Stage 1 & Stage 2 & & \multirow{6}{*}{0.2785} \\
\hline & 3.37 & 3.14 & $\begin{array}{c}0.4229 \\
(33)\end{array}$ & \\
\hline & Stage 2 & Stage 3 & & \\
\hline & 3.14 & 2.4 & $\begin{array}{c}0.0614 \\
(33)\end{array}$ & \\
\hline & Stage 3 & Stage 4 & & \\
\hline & 2.4 & 2.79 & $\begin{array}{c}0.4804 \\
(33) \\
\end{array}$ & \\
\hline \multirow{6}{*}{$\begin{array}{l}\text { Perceived } \\
\text { Importance }\end{array}$} & Stage 1 & Stage 2 & & \multirow{6}{*}{0.2785} \\
\hline & 4.15 & 4.11 & $\begin{array}{c}0.8386 \\
(33)\end{array}$ & \\
\hline & Stage 2 & Stage 3 & & \\
\hline & 4.11 & 3.68 & $\begin{array}{c}0.0735 \\
(33)\end{array}$ & \\
\hline & Stage 3 & Stage 4 & & \\
\hline & 3.68 & 3.80 & $\begin{array}{c}0.7382 \\
(33)\end{array}$ & \\
\hline
\end{tabular}

*2-tailed, confidence level 95\% 